Check for updates

Cite this: Metallomics, 2017, 9, 1304

Received 5th May 2017, Accepted 18th August 2017

DOI: $10.1039 / c 7 m t 00147 a$

rsc.li/metallomics

\section{Proteomic and genetic analysis of the response of $S$. cerevisiae to soluble copper leads to improvement of the antimicrobial function of cellulosic copper nanoparticles $\dagger$}

\author{
Xiaoqing Rong-Mullins, (D) $\ddagger^{a}$ Matthew J. Winans, $\left(\mathbb{D} \ddagger^{\mathrm{a}}\right.$ Justin B. Lee, ${ }^{a}$ \\ Zachery R. Lonergan, (D) $\S^{a}$ Vincent A. Pilolli, (D) I $^{a}$ Lyndsey M. Weatherly, ${ }^{a}$ \\ Thomas W. Carmenzind, ${ }^{\mathrm{b}}$ Lihua Jiang, ${ }^{\mathrm{c}}$ Jonathan R. Cumming, (D) ${ }^{\mathrm{a}}$ \\ Gloria S. Oporto (D) ${ }^{d}$ and Jennifer E. G. Gallagher (D)*a
}

\begin{abstract}
Copper (Cu) was used in antiquity to prevent waterborne and food diseases because, as a broad-spectrum antimicrobial agent, it generates reactive oxygen species, ROS. New technologies incorporating $\mathrm{Cu}$ into lowcost biodegradable nanomaterials built on cellulose, known as cellulosic cupric nanoparticles or c-CuNPs, present novel approaches to deliver $\mathrm{Cu}$ in a controlled manner to control microbial growth. We challenged strains of Saccharomyces cerevisiae with soluble $\mathrm{Cu}$ and c-CuNPs to evaluate the potential of c-CuNPs as antifungal agents. Cells exposed to $\mathrm{c}$-CuNPs demonstrated greater sensitivity to $\mathrm{Cu}$ than cells exposed to soluble $\mathrm{Cu}$, although $\mathrm{Cu}$-resistant strains were more tolerant than $\mathrm{Cu}$-sensitive strains of $\mathrm{c}$-CuNP exposure. At the same level of growth inhibition, $157 \mu \mathrm{M}$ c-CuNPs led to the same internal Cu levels as did $400 \mu \mathrm{M}$ $\mathrm{CuSO}_{4}$, offering evidence for alternative mechanisms of toxicity, perhaps through $\beta$-arrestin dependent endocytosis, which was supported by flow cytometry and fluorescence microscopy of c-CuNPs distributed both on the cell surface and within the cytoplasm. Genes responsible for genetic variation in response to copper were mapped to the ZRT2 and the CUP1 loci. Through proteomic analyses, we found that the expression of other zinc ( $\mathrm{Zn})$ transporters increased in $\mathrm{Cu}$-tolerant yeast compared to $\mathrm{Cu}$-sensitive strains. Further, the addition of $\mathrm{Zn}$ at low levels increased the potency of c-CuNPs to inhibit even the most $\mathrm{Cu}$-tolerant yeast. Through unbiased systems biological approaches, we identified $\mathrm{Zn}$ as a critical component of the yeast response to $\mathrm{Cu}$ and the addition of $\mathrm{Zn}$ increased the potency of the c-CuNPs.
\end{abstract}

Significance to metallomics

Saccharomyces cerevisiae has developed resistance to copper independently multiple times and provides an ideal model to assess the response of fungi to Cu. Previously, we demonstrated that c-CuNPs are an effective antibacterial material. In an effort to understand the mode of action of c-CuNPs, improve potency, ensure broad spectrum activity, and limit the development of antimicrobial resistance, the response of $S$. cerevisiae to c-CuNPs was characterized using proteomic and genetic approaches. c-CuNPs expose yeast to higher $\mathrm{Cu}$ levels and, by comparing the response of copper resistant to copper sensitive yeast, the role of $\mathrm{Zn}$ was uncovered. Through these interactions, we suggest that the antimicrobial effectiveness of metallic hybrid nanomaterials will enhance microbial control, which may offer a new and wide range of antimicrobial materials for public health and food safety.

\footnotetext{
${ }^{a}$ Department of Biology, West Virginia University, Morgantown, WV, USA. E-mail: jegallagher@mail.wvu.edu

${ }^{b}$ Department of Computer Science, Stanford University, Stanford, CA, USA

${ }^{c}$ Department of Genetics, Stanford University, Stanford University, Stanford, CA, USA

${ }^{d}$ Division of Forestry and Natural Resources, West Virginia University, Morgantown, WV, USA

$\dagger$ Electronic supplementary information (ESI) available. See DOI: 10.1039/c7mt00147a

$\$$ These authors contributed equally.

$\S$ Current address: Department of Pathology, Microbiology, and Immunology, Vanderbilt University, Nashville, TN, USA.

T Current address: Department of Biological Sciences and Chemical Engineering, Youngstown State University, OH, USA.
}

\section{A. Introduction}

Copper $(\mathrm{Cu})$ has been used since ancient times to prevent microbial growth because of its broad-spectrum activity coupled with multiple modes of toxicity. ${ }^{1}$ Excessive $\mathrm{Cu}$ induces damage by catalyzing the generation of reactive oxygen species (ROS). ${ }^{2}$ ROS generated by extracellular $\mathrm{Cu}$ oxidize lipids and proteins of the cell membrane ${ }^{3}$ and, if cells survive these lesions, then DNA damage can occur from the high levels of 
internal $\mathrm{Cu}^{4}{ }^{4}$ These mechanisms of toxicity and the response to $\mathrm{Cu}$ in microorganisms have been widely studied. ${ }^{5}$ Importantly, the expression of genes in response to $\mathrm{Cu}$ is highly regulated to maintain a fine balance of this essential, yet toxic, trace metal within the cytoplasm. ${ }^{6,7}$

Nanotechnology is a transformative tool that can be used to develop and enhance high-value products from renewable and biocompatible raw materials such as wood..$^{8-12}$ Cellulose, as the predominant component of woody biomass, can be utilized not only commercially where bio-compatibility and biodegradability are relevant, but also as a support structure for nanoparticle formation in novel applications. The use of the cellulose nanostructure as a template and stabilizer for metallic nanoparticles expands the potential applications of nanomaterials. ${ }^{13}$ Cellulosic cuprous nanoparticles (c-CuNPs) display effective antimicrobial activity against a non-pathogenic Escherichia coli DH5 $\alpha .^{14,15} \mathrm{c}$-CuNPs contain reduced copper $(\mathrm{Cu}(\mathrm{I}))$, which is thought to be slowly released as $\mathrm{Cu}(\mathrm{I})$ and then oxidized making $\mathrm{Cu}(\mathrm{II})$ available to interact with biological molecules leading to toxicity.

Improving c-CuNPs depends on understanding their range of functions in order to manufacture products with increased antimicrobial effectiveness. We have developed a cost-effective hybrid nanomaterial built on a cellulosic scaffold with $\mathrm{Cu}(\mathrm{I})$ chemically linked to cellulose. ${ }^{16}$ To understand how yeast respond to $\mathrm{Cu}$ delivered in c-CuNPs, we carried out toxicological and quantitative proteomic analyses on genetically diverse yeast strains. c-CuNPs delivered more $\mathrm{Cu}$ to yeast cells compared to soluble $\mathrm{CuSO}_{4}$, and this may result from the endocytic uptake of c-CuNPs. The levels of hundreds of proteins changed in response to $\mathrm{Cu}$ exposure, and yeast strains that do not tolerate $\mathrm{Cu}$ fail to increase expression of Zrt1, a high affinity zinc (Zn) transporter. Furthermore, a genome-wide quantitative trait loci (QTL) analysis uncovered a role for $\mathrm{Zn}$ transporters in the $\mathrm{Cu}$ response. The genetic variation in the low-affinity membrane transporter, Zrt2, directly contributed to variation of $\mathrm{Cu}$ tolerance, while yeast lacking Zrt1 or Zrt3 were sensitive to high levels of $\mathrm{Cu}$. Supplementing $\mathrm{Zn}$ decreased the growth of all yeast strains tested when also challenged with c-CuNPs. Understanding the interdependence of metal tolerances provides insights into improving the antimicrobial properties of metal-based materials.

\section{B. Materials and methods}

\section{Yeast strains and plasmids}

The S288c strains used included strains S96 (MATa lys $5^{17}$ ) and GSY147 (MATa prototroph ${ }^{18}$ ). YJM789 (MATalpha lys $2^{17,19}$ ) was the parent of YJM789K5a (MATa prototroph). YJM789K5a was generated by transforming a PCR product containing LYS2 into YJM789 and then backcrossed to HS959 (MATa lys2) that is otherwise isogenic to YJM789. All S288c strains displayed a similar copper resistance. Both YJM789 strains were copper sensitive. Other strains used were AWRI1631, RM11, and YJM339. ${ }^{20-22}$ The haploid recombinant segregant collection between YJM789 and S96 was previously generated. ${ }^{17}$ Knockout strains were previously described. ${ }^{23}$ Cloning of ZRT2 alleles was carried out by PCR amplified from genomic DNA using primers as follows: 5'ZRT2 GTACCTGCAGGCGTCCTAATGAAAATGGAGG and 3'ZRT2 TTCCCGGGATTACTCTGCCCTTTTC. Endogenous promoter and terminator sequences within 580 nucleotides upstream of the start and 277 nucleotides downstream of the stop codons were included. Genes were cloned into the SbfI and XmaI sites of the pGS36 plasmid with the hygromycin resistance marker. ${ }^{18}$ Plasmids were kept under selection with hygromycin after LiAc chemical transformations.

\section{Media and chemicals}

All haploid yeast strains were grown in yeast minimal media (YM), which includes $2 \%$ dextrose, $6.7 \mathrm{~g} \mathrm{~L}^{-1}$ yeast nitrogen base, and $20 \mathrm{~g} \mathrm{~L}^{-1}$ agar in solid media. In liquid media, the agar was omitted. YM was, when needed, supplemented with lysine, methionine, uracil, leucine, and histidine. Plasmids were maintained by addition of $250 \mu \mathrm{g} \mathrm{mL}^{-1}$ hygromycin. All antioxidants were added to solid media when it had cooled to $55^{\circ} \mathrm{C}$ and used within 24 hours. Chronic exposure was defined as two days of exposure, while acute exposure was defined as two hours of exposure. Viability assays were carried out in liquid culture in biological triplicates. Yeast were grown to log-phase and split into subcultures. Subcultures served as controls, receiving no added $\mathrm{Cu}$; were soluble $\mathrm{Cu}$-treated, receiving various concentrations of $\mathrm{CuSO}_{4} \cdot 5 \mathrm{H}_{2} \mathrm{O}$ (Ricco Chemicals, CAS 7732-18-5); or received c-CuNPs. Carboxymethyl cellulose (CMC) copper nanoparticles (c-CuNPs) were created and physically characterized as previously reported, ${ }^{16}$ where $\mathrm{Cu}$ is reduced and bound onto free hydroxyls of the cellulose scaffold. $10 \mu \mathrm{g} \mathrm{mL}^{-1}$ of c-CuNP corresponded to $157 \mu \mathrm{M}$ of soluble $\mathrm{Cu}$ determined by atomic absorption spectrometry (AAS). Yeast medium is acidic (pH 5), which would cause dissociation and oxidization of $\mathrm{Cu}$ from the c-CuNPs. Indeed, $27 \%$ more free copper was found in c-CuNPs suspended in YM than in water alone.

\section{Atomic absorption spectrometry}

Strains YJM789K5a, GSY147, RM11, and YJM339 were grown in YM media in triplicate to the log phase. The control samples (YM) were collected. The remaining cultures were treated with $400 \mu \mathrm{M} \mathrm{CuSO}_{4}$ or $157 \mu \mathrm{M} \mathrm{Cu}$ as c-CuNPs $\left(10 \mu \mathrm{g} \mathrm{mL}{ }^{-1}\right.$ of CMC) for 2 hours. For cell collection, an equal number of cells, as determined by optical density at $600 \mathrm{~nm}$, was obtained (equivalent to $4 \mathrm{ODu}$ ). These samples were centrifuged and washed twice with distilled water. One ODu was separated for protein quantification. Samples were split, frozen in liquid nitrogen and stored at $-80{ }^{\circ} \mathrm{C}$. Soluble protein concentration was determined via Bradford assay. For AAS, the cell pellets were treated with $600 \mu \mathrm{L}$ of concentrated $\mathrm{HNO}_{3}$ and $200 \mu \mathrm{L}$ of $30 \% \mathrm{H}_{2} \mathrm{O}_{2}$ for digestion. These solutions were transferred to glass tubes and placed in a boiling water bath for 2 hours until clear. A 1:10 dilution with distilled water was analyzed for $\mathrm{Cu}$ at $324.8 \mathrm{~nm}$. Copper concentrations were given in $\mathrm{mg} \mathrm{L}^{-1}$, adjusted for dilution, and normalized to soluble protein concentration for each sample. AAS was performed across four days, and a total average for the four repeated samples was determined for each day. From these values, the 
overall average was determined. To calculate the correction factor for each day's analysis, the overall average was divided by the daily average. This correction factor was then applied to all the values for that particular day, prior to dilution adjustments.

\section{Staining of yeast cells and cellulose copper nanoparticles for flow cytometry and microscopy}

Cells of each strain were cultured from frozen stock in YM media to the log phase and harvested by centrifugation. The cells were then transferred to $10 \mathrm{mM}$ 4-(2-hydroxyethyl)-1piperazineethanesulfonic acid (HEPES) buffer ( $\mathrm{pH}$ of 7.4) containing 5\% Rhodamine B (RhodB) was added to final concentration of $100 \mathrm{nM}$, and the cells were incubated at room temperature for 20 minutes in the dark. c-CuNPs were added to phosphate buffered saline (PBS) to a concentration of $400 \mu \mathrm{M}$ with Fluorescein isothiocyanate (FITC) in dimethyl sulfoxide (DMSO) to a final concentration of $2.568 \mu \mathrm{M}$. The FITC-dyed PBS nanoparticle solution was incubated in the dark for 8 hours at $4{ }^{\circ} \mathrm{C}$. Because excess FITC could not be removed from the solution, 5.136 $\mathrm{mM}$ in DMSO was added to PBS to a final concentration of $2.568 \mu \mathrm{M}$ and incubated in the dark for 8 hours at $4{ }^{\circ} \mathrm{C}$ to serve as a control.

DMSO was purchased from Biotium (Hayward, CA). A four laser LSR/Fortessa (BD Biosciences, San Jose CA) with BD FACS Diva software (BD Biosciences) located in the WVU Flow Cytometry \& Single Cell Core Facility was used to collect flow cytometric data. Cells of each strain were transferred from HEPES buffer, treated, and transferred to PBS. To determine the extent of association of c-CuNPs with the yeast cell wall, $1 \mathrm{~mL}$ of PBS containing 1 million dyed cells was added to $1 \mathrm{~mL}$ of $400 \mu \mathrm{m}$ dyed c-CuNP PBS solution. To control for FITC labeling of cells, $1 \mathrm{~mL}$ of PBS containing 1 million dyed cells was added to $1 \mathrm{~mL}$ of $2.568 \mu \mathrm{M}$ FITC in PBS. Solutions were allowed to incubate at $30{ }^{\circ} \mathrm{C}$ for 2 hours. Samples in PBS were analyzed on an LSR Fortessa (BD Biosciences San Jose CA) using BD FACS Diva version 8.0 software (Fig. S1, ESI $\dagger$ ). A total of 10000 events were collected/sampled and the median fluorescence intensity for each sample was calculated. Also, in order to ensure that the FITC signal only came from c-CuNPs that were inside the yeast, trypan blue was added to the samples prior to analysis on the flow cytometer.

After treatment, samples were harvested by centrifugation and re-suspended in $1 \mathrm{~mL}$ PBS containing $4 \%$ paraformaldehyde and incubated for 30 minutes at $30{ }^{\circ} \mathrm{C}$. Cells were washed twice with PBS and re-suspended in $500 \mu \mathrm{L}$ of $80 \%$ glycerol before sonicating at $10 \%$ amplitude for six seconds with one second pulses for 5 intervals of 1 second bursts on a Branson model SSE-1 Sonifier. Concanavalin A (Sigma - L7647) coated microscope slides were utilized to mount $10 \mu \mathrm{L}$ of the samples and sealed with clear fingernail polish. Fluorescent yeasts were viewed using a laser scanning confocal microscope (Olympus FV1000) equipped with red/green HeNe and argon lasers. Images were acquired using a $60 \times$ oil immersion magnification optical objective. Distances between confocal planes were optimized for the objective using Fluoview software (FV10-ASW Version 04.00.02.09). Pixel resolution was adjusted for best resolution capable of performing a z-stack scan. Images were only modified for contrast enhancement.

\section{Viability assay}

After two hours with $400 \mu \mathrm{M}$ of copper or $157 \mu \mathrm{M}$ c-CuNPs, the cultures were washed twice with water, and the $\mathrm{OD}_{600}$ was measured. 0.1 OD unit (ODu) of each sample was diluted 100fold and $100 \mu \mathrm{L}$ was plated on YPD. The number of untreated colonies that grew was considered $100 \%$ viability, and the viability of treated cells was taken as a percentage of untreated cells.

\section{Proteomics}

To measure the global proteomic changes of S288c and YJM789 in response to $\mathrm{Cu}$, cells were treated for 90 minutes in YM with or without $800 \mu \mathrm{M} \mathrm{CuSO}$. Peptides were prepared using a modified FASP method. ${ }^{24}$ Treated cells were harvested by briefly spinning down 5 ODu of cells, washing once with water and then freezing cell pellets in liquid nitrogen in $2 \mathrm{~mL}$ screw cap tubes. Cells were lysed in 4\% SDS, $100 \mathrm{mM}$ DTT, and $100 \mathrm{mM}$ Tris pH 8.5 in a ratio of $1: 10 \mathrm{v} / \mathrm{v}$ cell pellet to buffer. $0.5 \mathrm{~mm}$ zirconium beads were added and the cells were lysed in a Fastprep for $3 \times 20$ seconds at speed 5 with a 5 minute rest at room temperature. Using a 24-gauge needle, the bottom of the tube was punctured and placed into a $2 \mathrm{~mL}$ low protein binding locking cap tube. All liquid and cellular debris were then spun at $1000 \mathrm{rpm}$ into a $2 \mathrm{~mL}$ tube. The tubes were incubated at $95{ }^{\circ} \mathrm{C}$ for 4 minutes. Cellular debris was pelleted for 10 minutes at $14000 \mathrm{rpm}$ at room temperature. The supernatant was transferred to new tubes. Protein concentration was calculated using Bradford reagent on a 1:100 diluted sample. $200 \mu \mathrm{g}$ of protein was diluted with $8 \mathrm{M}$ urea/100 $\mathrm{mM}$ Tris $\mathrm{pH} 8.5$ to a final SDS concentration of $1 \%$ and transferred to a Microcon YM-30 column. The Microcon columns were spun at $10000 \mathrm{rpm}$. Proteins were washed five times with $8 \mathrm{M}$ urea/100 mM Tris pH 8.5 and resuspended in $100 \mu \mathrm{L}$ of $0.05 \mathrm{M}$ idoacetamide in $8 \mathrm{M}$ urea/0.1 M Tris $\mathrm{HCl}$ 8.5. The samples were alkylated for 45 minutes in the dark. Liquid was spun through the Microcon. The buffer was exchanged for $200 \mathrm{mM}$ TEAB by washing the proteins five times. Protein concentrations were retested using a BCA kit (Thermo Fisher Scientific) on 1:100 diluted samples. Trypsin was freshly dissolved in $200 \mathrm{mM}$ TEAB and incubated at $30{ }^{\circ} \mathrm{C}$ for 20 minutes. Trypsin was incubated with proteins on the Microcon wrapped in parafilm overnight at $37^{\circ} \mathrm{C}$ at $1: 20$ dilution. Digested peptides were spun through the Microcon and collected into fresh tubes. The concentration of peptides was approximated, and $5 \mu \mathrm{g}$ of peptides were labeled with Thermo Fisher Tandem Mass Tags 6plex in a 10:4.1 ratio according to the manufacturer's instructions for 1.5 hours at room temperature. The reaction was quenched with $5 \%$ hydroxylamine diluted in $200 \mathrm{mM}$ TEAB. Equal amounts of labeled peptides were mixed and dried.

Peptides were resuspended in $100 \mathrm{mM}$ ammonia formate at pH 10 and separated by reverse phase chromatography at high $\mathrm{pH}$ in the first dimension, followed by an orthogonal separation at low $\mathrm{pH}$ in the second dimension. In the first dimension the mobile phases were buffer A: $20 \mathrm{mM}$ ammonium formate at $\mathrm{pH}$ 
10 and buffer B: acetonitrile. Peptides were separated on a Xbridge $300 \mu \mathrm{m} \times 5 \mathrm{~cm}$ C18 $5.0 \mu \mathrm{m}$ column (Waters) using a

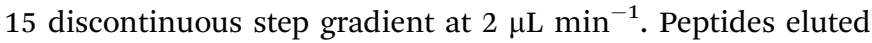
off from the first dimension were trapped by a Symmetry $180 \mu \mathrm{m} \times 2 \mathrm{~cm} \mathrm{C18} 5.0 \mu \mathrm{m}$ trap column (Waters). In the second dimension, peptides were loaded into an in-house packed $75 \mu \mathrm{m} \mathrm{ID} / 15 \mu \mathrm{m}$ tip ID $\times 20 \mathrm{~cm}$ C18-AQ $3.0 \mu \mathrm{m}$ resin column with buffer A ( $0.1 \%$ formic acid in water). Peptides were separated with a linear gradient from $5 \%$ to $30 \%$ buffer B $(0.1 \%$ formic acid

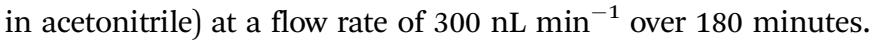
Each sample separation was repeated three times.

Peptides were identified by using a linear trap quadrupole (LTQ)-Orbitrap Velos instrument (Thermo Fisher Scientific). The mass spectrometer was run in a data dependent mode. One survey scan acquired in the Orbitrap mass analyzer with resolution 60000 was followed by MS/MS of the 10 most intense peaks with charge state $\geq 2$ and above an intensity threshold of 5000. Peptides were fragmented in the high collisional cell (HCD) with normalized collision energy of $40 \%$ and activation time of $0.1 \mathrm{~s}$. The MS/MS scan was acquired in the Orbitrap at resolution of 7500 .

Peptides were identified and quantitated using Proteome Discoverer 1.4.1.14 (Table S1, ESI $\dagger$ ). Spectra were searched against a protein database consisting of all the S288c (http:// downloads.yeastgenome.org/sequence/S288C_reference/genome_ releases/S288C_reference_genome_R64-1-1_20110203.tgz) and YJM789 (http://downloads.yeastgenome.org/sequence/strains/ YJM789/YJM789_Stanford_2007_AAFW02000000) proteins available in the Saccharomyces Genome Database (http://www.yeastgenome. org). Common contaminants such as human keratin and trypsin were also included in the database to prevent peptides of those contaminants from being falsely identified as yeast peptides (Table S2, ESI †). TMT6plex was used for quantification labeling according to the manufacturer's instructions and the six isobaric labels of 126-131 Da were assigned to samples as follows: 126 S288c, YM, replicate 1; 127 - S288c, YM, replicate 2; 128 - S288c, $\mathrm{Cu}$ treated, replicate $1 ; 129$ - S288c, Cu treated, replicate 1; 130 YJM789, YM; 131 - YJM789, Cu treated.

The default method used by Proteome Discoverer to quantify protein fold change from peptide intensities is to calculate the median intensity ratio between two isobaric labels for all the peptide spectrum matches (PSMs) associated with the protein in question. This method is problematic when a peptide sequence is identified in multiple PSMs where ratios have large variation. For example, a peptide can have different phosphorylation states between two treatments, and consequently show very different ratios for the phosphorylated PSMs and the unphosphorylated PSMs. This type of variation can skew quantification results when there are only a few PSMs usable for quantification; therefore, we used different methods than the Proteome Discoverer default for protein quantification. For each peptide sequence identified by Proteome Discoverer, the reporter ion intensities of all PSMs associated with this peptide were summed into the total intensity for this peptide in each sample. For each protein, only its unique (not belonging to any other protein) peptides of high to middle confidence (false discovery rate $0.01-0.05$ ) were considered usable for quantification. Four comparisons, each between two experimental scenarios, were performed by calculating intensity ratios of reporter ions: (1) S288c, Cu vs. YM - (128 + 129)/(126 + 127); (2) YJM789, Cu vs. YM - 131/130; (3) YJM789 vs. S288c, YM - $130 \times$ $2 /(126+127)$; (4) YJM789 vs. S288c, Cu - $131 \times 2 /(128+129)$. For the comparisons between strains, (3) and (4), only peptides showing no sequence polymorphisms between the two strains were considered usable for quantification. Four methods were used to calculate protein ratios for each comparison: (1) 'means then ratio' - the mean of all the usable peptides belonging to this protein was calculated for each experimental scenario, then the ratio between the two scenarios was calculated from the two means; (2) 'medians then ratio' - the median of usable peptides was calculated for each scenario, then the ratio was calculated from the two medians; (3) 'ratios then mean' - the ratio between the two scenarios was calculated for each usable peptide, then the mean of all the ratios was calculated; (4) 'ratios then median' - the ratio was calculated for each usable peptide, then the median of all the ratios was calculated. For each of the four methods and each comparison of two scenarios, the resulting ratios for all the proteins were divided by the median of the ratios for normalization. This normalization method assumes that the majority of reported proteins do not change much in each comparison, which was the case in our experiment (see Results). For each comparison, only the proteins showing ratios $>2$ or $<0.5$ by all the four methods were included in Table S1 (ESI $\dagger$ ). The ratios calculated using method (1) 'means then ratio' were transformed into logarithms of 2 (two).

63563 PSMs were reported with high to middle confidence (false discovery rate $0.01-0.05$ ), representing 27794 unique peptide sequences. Peptides were labeled with isobaric mass tags for quantification with Tandem Mass Tag (TMT). The TMT labeling rates of these PSMs were 92.7-97.3\%. 4431 yeast proteins were reported containing at least one peptide with middle to high confidence (each case of two homologous proteins from S288c and YJM789 were counted as one protein), among which 2991 were quantified with at least two unique peptides and considered for differential abundance quantification. 112 proteins showed greater than two-fold change (absolute value of $\log 2$ (fold change) or $|\log 2 f c|>1$ ) between strains and/or copper treatments (Table S1, ESI $\dagger$ ) by all the four calculation methods for fold change.

\section{Quantitative trait loci studies on copper response}

Strains from the recombinant haploid segregant collection ${ }^{17}$ from crossing S288c (S96) and YJM789 were grown to saturation in YM supplemented with lysine. The cells were then diluted to $0.2 \mathrm{OD}_{600}$ in $200 \mu \mathrm{L}$ in $\mathrm{YM}$ or YM with $50 \mu \mathrm{M} \mathrm{CuSO}_{4}$ in triplicate in 96 well plates. The plates were sealed and readings taken every hour in a TECAN M200, an automatic plate reader with no shaking to mimic growth on solid media. The culture density at 12 hours (late-log phase) and at 18 hours (endpoint or stationary phase) was used to map quantitative trait loci (QTL). All readings in $\mathrm{Cu}$ were subtracted from the same strain grown in YM for QTL values (Table S3, ESI $\dagger$ ). For each locus, we calculated a growth score and a significance score. To calculate the growth score, all 
strains that inherited the segregant YJM789 (1) allele were assigned to group 1, and all strains that inherited the segregant S96 (2) allele were assigned to group 2. Average growth was calculated for strains in group 1 and was subtracted from the average growth for strains in group 2. The calculations resulted in the growth score. A positive growth score indicates that the segregant 1 allele leads to high growth and $\mathrm{Cu}$ resistance while a negative growth score indicates the segregant 2 allele confers $\mathrm{Cu}$ sensitivity. The significance score was also calculated, which is the probability of these growth scores occurring if the alleles were assigned randomly. To calculate the significance score, each yeast strain was randomly assigned to group 1 or group 2 regardless of which allele was inherited. The growth score was calculated given these 2 randomly assigned groups and repeated 100000 times using a Monte Carlo simulation. The resulting distribution over growth scores was approximately normal. This normal distribution was used to calculate the significance score. We then studied the loci that have large magnitude growth scores and high significance scores for 12 hour growth (Table S4) and 18 hour growth (Table S5) (ESI $\dagger$ ).

\section{Results}

\section{Clinical isolates are more sensitive to copper than agricultural isolates}

$S$. cerevisiae is among the oldest domesticated species and has evolved high tolerances to copper independently multiple times both in the wild and in lab-evolution experiments. ${ }^{5,25-29}$ To assess the antimicrobial potency of copper incorporated onto cellulosic nanoparticles, genetically diverse yeasts were incubated in liquid culture with different concentrations of c-CuNPs. ${ }^{16}$ The agricultural isolates AWRI1631, ${ }^{20} \mathrm{RM} 11,{ }^{21,30,31}$ and $\mathrm{S} 288 \mathrm{c}^{32,33}$ were resistant to $\mathrm{Cu}$ whereas YJM339 ${ }^{19}$ and YJM789, ${ }^{19,34}$ clinical isolates of yeast, had lower $\mathrm{Cu}$ tolerances (Fig. 1A). The c-CuNPs were diluted to a level that would inhibit growth of YJM789 to a similar degree to $400 \mu \mathrm{M}$ of soluble $\mathrm{Cu}$ when measured for growth in a plate reader without shaking, mimicking their growth on solid media. Both $30 \mu \mathrm{g} \mathrm{mL} \mathrm{m}^{-1}$ (by CMC concentration) of c-CuNPs and $400 \mu \mathrm{M}$ of soluble copper decreased the growth of YJM789 by $90 \%$ compared to YM media. Similarly, both the soluble $\mathrm{Cu}$ and c-CuNPs embedded into solid agar media inhibited the growth of yeast, with the agricultural isolates being more resistant than the clinical isolates (Fig. 1B). However, growth patterns on agar suggested that c-CuNPs may be more toxic than soluble $\mathrm{Cu}$, with growth at $10 \mu \mathrm{g} \mathrm{mL} \mathrm{m}^{-1} \mathrm{c}-\mathrm{CuNPs}$ inhibiting growth to the same extent as $200 \mu \mathrm{M} \mathrm{Cu}$ (Fig. 1B).

Because copper can catalyze the generation of reactive oxygen species, ${ }^{2}$ we tested the ability of antioxidants to quench free radicals induced by soluble copper and c-CuNPs. Both glutathione (GSH) and $N$-acetylcysteine (NAC), a glutathione precursor, rescued growth inhibition by soluble copper in clinical strains YJM789 and YJM339 (Fig. 2). No growth rescue was detected with oxidized glutathione (GSSH) or ascorbic acid (another antioxidant) in the presence of $\mathrm{Cu}$ for YJM789, but there was a slight improvement for YJM339. When cells were
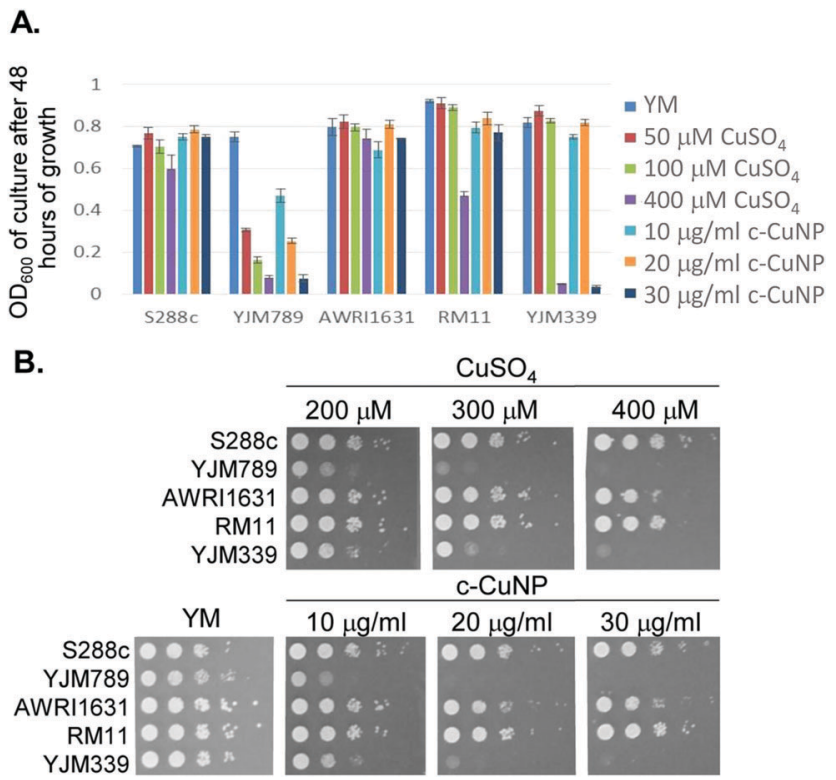

Fig. 1 Impact of genetic variation in S. cerevisiae to soluble copper and cellulosic hybrid copper nanoparticles. (A) Growth of yeast in liquid culture in synthetic media (YM) with the addition of dilutions of $\mathrm{CuSO}_{4}$ and c-CuNPs. (B) Serial dilutions of genetically diverse $S$. cerevisiae with dilutions of $\mathrm{CuSO}_{4}$ and c-CuNPs on solid YM.

treated with nicotinamide (NAM) and ascorbic acid (AA), the $\mathrm{Cu}$ tolerance of YJM339, but not YJM789, increased slightly, suggesting that, although YJM789 and YJM339 are Cu sensitive, there are other genetic differences that affect $\mathrm{Cu}$ response. However, NAC could not rescue growth inhibition caused by c-CuNPs. While NAC can function as an antioxidant when it is imported into cells, NAC is the precursor to glutathione, which is more potent at reducing ROS. $^{35}$ Therefore, while the pattern of c-CuNP sensitivity approximately mirrored soluble $\mathrm{Cu}$ sensitivity, the difference in NAC rescue suggests differences in Cu delivery, and likely, cellular internalization, between cells exposed to soluble $\mathrm{Cu}$ and c-CuNPs.

To determine how much $\mathrm{Cu}$ is imported into yeast, internal copper levels were measured by atomic absorption spectrometry (AAS). When grown in YM, YJM789 has three-fold less

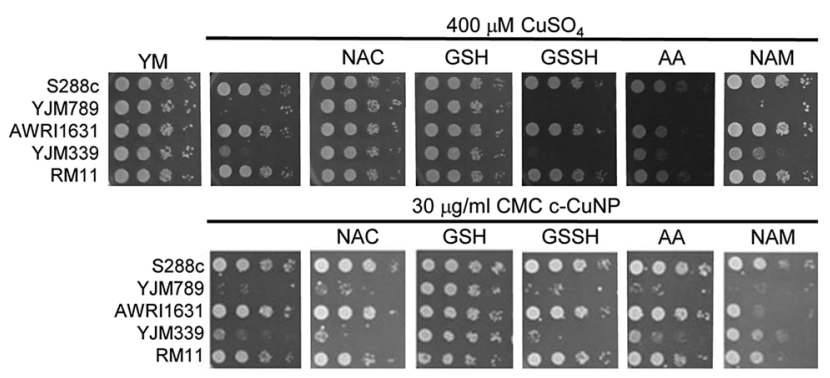

Fig. 2 Rescue of copper nanoparticle sensitivity with antioxidants. Serial dilutions of genetically diverse $S$. cerevisiae on synthetic media (YM) with the addition of $400 \mu \mathrm{M} \mathrm{CuSO}_{4}$ or C-CuNPs and supplemented with $100 \mu \mathrm{M}$ of antioxidants as listed: $N$-acetylcysteine (NAC), glutathione (GSH), oxidized glutathione (GSSH), ascorbic acid (AA) and nicotinamide (NAM). Haploid strains were serially diluted and spotted onto solid media. After 2 days of growth at $30^{\circ} \mathrm{C}$, the plates were photographed. 
Cu than YJM339 or S288c. Furthermore, YJM789 accumulates as much $\mathrm{Cu}$ as RM11, a Cu-resistant strain (Fig. 3). Thus, basal untreated internal $\mathrm{Cu}$ levels do not correspond to $\mathrm{Cu}$ sensitivity. Treatment with GSH or NAC did not significantly change internal copper levels except for YJM789, in which cellular $\mathrm{Cu}$ increased with NAC to levels comparable to S288c and YJM339 (Fig. 3). Treatment with $400 \mu \mathrm{M} \mathrm{Cu}$ increased internal $\mathrm{Cu}$ concentrations in all strains, although to varying extents, by between 9- and 90-folds (Fig. 3). YJM789 and YJM339 had $\sim 0.8 \mu \mathrm{g}$ of internal $\mathrm{Cu}$ per $\mathrm{mg}$ of protein, whereas Cu-resistant strains S288c and RM11 had levels 66\% to 53\% lower, respectively. To establish similar internal levels of copper from c-CuNPs to the levels from $400 \mu \mathrm{M}$ soluble copper, the amount of c-CuNPs was decreased to $157 \mu \mathrm{M}$ of $\mathrm{Cu}$ bound to $\mathrm{CMC}\left(=10 \mu \mathrm{g} \mathrm{mL}^{-1}\right.$ $\mathrm{CMC}$ ). The acute exposure of yeast to $157 \mu \mathrm{M} \mathrm{Cu}$ as c-CuNPs led to higher $\mathrm{Cu}$ accumulation than levels measured when exposed to soluble $\mathrm{Cu}$ (Fig. 3): the internal $\mathrm{Cu}$ concentrations of yeast treated with $157 \mu \mathrm{M} \mathrm{Cu}$ as c-CuNPs were similar to those of yeast treated with 2.5 times higher levels of $\mathrm{CuSO}_{4}$. Co-treatment of yeast with glutathione and soluble $\mathrm{Cu}$ or c-CuNPs increased $\mathrm{Cu}$ uptake by 4 - to 10 -fold compared to copper treatments alone. The internal levels of $\mathrm{Cu}$ for GSH- and NAC-treated yeast, in general, were increased and similar irrespective of the copper source with two exceptions. YJM798 accumulated $\mathrm{Cu}$ from c-CuNPs when supplemented with GSH and RM11 exposed to c-CuNPs and NAC had lower internal $\mathrm{Cu}$ levels.

Because the c-CuNPs increased the efficiency of $\mathrm{Cu}$ delivery and lacked the NAC rescue to c-CuNP toxicity, we turned our focus to additional paths of $\mathrm{Cu}$ delivery by c-CuNPs. c-CuNPs are 10-20 nm particles with a unique three-dimensional spherical structure built on a cellulose scaffold. ${ }^{16}$ To assess the interaction of c-CuNPs with the outer surface of yeast cells, yeast cells were measured by flow cytometry in the presence of c-CuNPs. The yeasts were stained with Rhodamine $\mathrm{B}$, which crosses cell membranes and is sequestered by mitochondria without

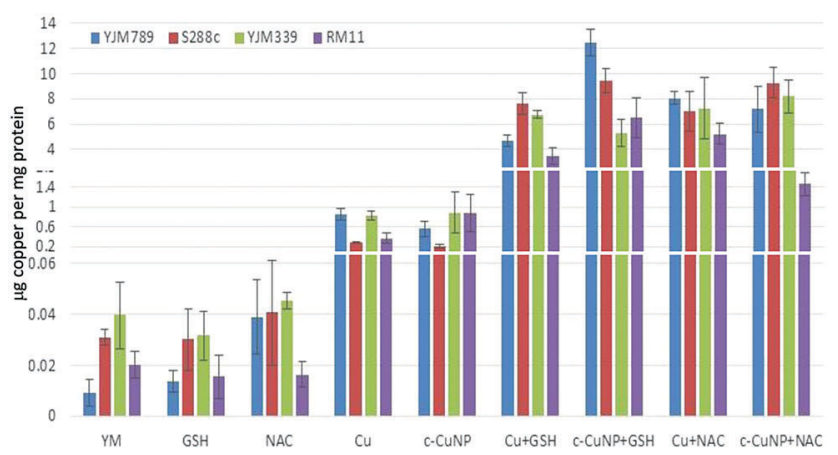

Fig. 3 Internal levels of copper in yeast treated with different sources of copper and antioxidants. Internal levels of copper were measured by atomic absorption spectrometry and normalized to the protein content The following treatments are displayed in this graph: YM, $157 \mu \mathrm{M} \mathrm{c}$-CuNPs, $400 \mu \mathrm{M} \mathrm{CuSO}_{4}, 100 \mu \mathrm{M} \mathrm{GSH}, 100 \mu \mathrm{M}$ NAC, $157 \mu \mathrm{M}$ c-CuNPs $+100 \mu \mathrm{M}$ GSH, $157 \mu \mathrm{M}$ c-CuNPs $+100 \mu \mathrm{M} \mathrm{NAC}, 400 \mu \mathrm{M} \mathrm{CuSO}_{4}+100 \mu \mathrm{M} \mathrm{GSH}$, and $400 \mu \mathrm{M} \mathrm{CuSO}_{4}+100 \mu \mathrm{M}$ NAC. The graph is rescaled to better show the concentrations of the controls. The average of three independent samples for each treatment was determined and error bars were plotted. inducing cell lysis, while c-CuNPs were stained with FITC. Because c-CuNPs labeled with FITC are too small to be directly detected by flow cytometry, FITC labeling can only be measured when c-CuNPs are associated with yeast cells (Fig. S1, ESI $\dagger$ ). The fluorescence intensities of S288c, YJM789, YJM339, and RM11 cells incubated for two hours with $157 \mu \mathrm{M}$ of FITC pre-stained c-CuNPs increased compared to yeast cells alone (Fig. 4A), suggesting the binding or uptake of c-CuNPs by yeast cells. In addition, a greater proportion of cells of YLM789 and YJM339 accumulated FITC-labeled c-CuNPs (Fig. 4A) and they accumulated these to a greater extent (Fig. 4B) than the S288c or RM11 lines.

To evaluate the physical location of c-CuNPs on yeast cells, cells exposed to FITC-labeled c-CuNPs were further treated with trypan blue, which quenches FITC fluorescence. Trypan blue does not enter living cells and can only quench FITC if the dye was physically located outside the yeast. This addition decreased the fluorescence intensity of FITC-stained c-CuNPs associated with yeast (Fig. 4B). To confirm that c-CuNPs were both outside and inside, the yeasts were again treated with c-CuNPs and CMC (cellulose backbone of the nanoparticles). Further examination revealed two populations of cells: most of the FITC stained c-CuNPs appeared as speckled spots on the outside of the yeast, while about $10 \%$ of the cells exhibited fluorescence inside the cells as seen through z-stack using confocal microscopy (Fig. 4C). The extracellular and intracellular fluorescence was not dependent on the presence of $\mathrm{Cu}$ on $\mathrm{CMC}$ (Fig. 4C).

To determine whether c-CuNPs were actively internalized by endocytosis, the viability of mutants in aly1 and aly2, arrestins that act as adapters for clatherin-mediated endocytosis, ${ }^{36}$ were evaluated. Also tested were mutants of fre 1 and fre $2,{ }^{37,38}$ which reduce oxidized $\mathrm{Cu}$ for transport by $\mathrm{Ctr} 1$. These knockout strains were constructed in the BY4741 strain background that is related to $\mathrm{S} 288 \mathrm{c} .^{23}$ Testing the viability of yeast under acute exposure can reveal smaller differences in sensitivity and determine if changes in viability to c-CuNP liquid culture is different from on plates. Cells were grown under similar conditions as when measuring internal copper levels (Fig. 3). When endocytosis is affected by deletion of Aly1 and Aly2, cellular viability was restored in the presence of c-CuNPs but not soluble copper (Fig. 4D). Loss of Fre1 and Fre2 increased cellular viability in the presence of soluble copper but not c-CuNPs (Fig. 4D).

Previous assessment of growth inhibition with c-CuNPs was carried out under chronic 2 day exposure measuring changes in growth in solid media (e.g., Fig. 1 and 2). Physical interactions between the yeast and c-CuNPs were measured under acute exposure in liquid media (e.g., Fig. 3 and 4). Viability assays were undertaken to evaluate the impact of soluble $\mathrm{Cu}$ and c-CuNPs on cell survival under acute exposure at comparable total $\mathrm{Cu}$ concentrations. Overall, the greater toxicity of c-CuNPs is evident across all isolates, with near complete loss of viability following exposure to $400 \mu \mathrm{M} \mathrm{Cu}$ as c-CuNPs (Fig. 5). Differential resistance of the isolates was also confirmed, with $\mathrm{S} 288 \mathrm{c}$ and RM11 exhibiting greater viability than YJM789 or YJM339 regardless of the $\mathrm{Cu}$ source (Fig. 5). 
A.

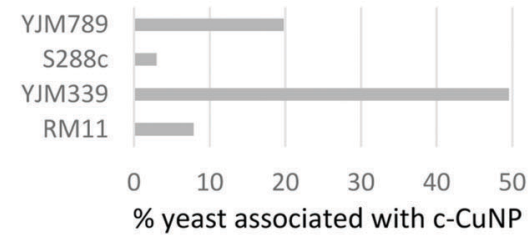

B.
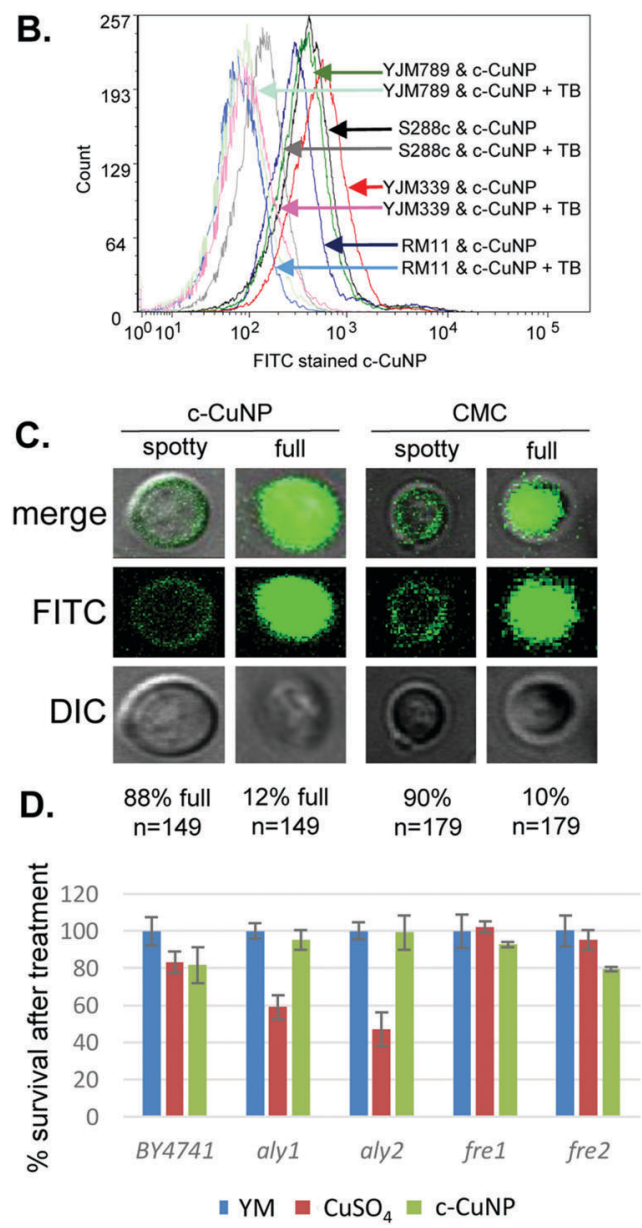

Fig. 4 Physical interaction of copper nanoparticles and yeast cells (A). Flow cytometry measuring interaction between FITC stained c-CuNPs and Rhodamine B stained yeast strains, YJM789 (YJM789K5a), S288c (GSY147), RM11 and YJM339. $157 \mu$ M. Dual stained C-CuNPs and yeast are graphed as a percentage. Yeasts were stained with Rhodamine B. C-CuNPs and yeasts were then incubated for two hours. (B) Flow cytometry of FITC stained c-CuNPs associated with yeast were quenched with trypan blue (TB). Arrows point to peaks as they shift in fluorescence. The number of cells measured is on the $x$-axis as count. Light lines represent yeast with c-CuNPs and solid lines represent yeast and C-CuNPs treated with trypan blue. (C) Confocal microscopy of yeast (GSY147) and FITC stained c-CuNPs. (D) Cellular viability of yeast knockouts in the BY4741 (S288c) background normalized to yeast grown in YM supplemented with required amino acids treated with $400 \mu \mathrm{M} \mathrm{CuSO}_{4}$ or $157 \mu \mathrm{M}$ c-CuNPs.

\section{Genetic and proteomic responses to copper in genetically diverse yeast}

The four diverse strains of yeast used in this study have underlying genetic differences that contribute to variation in $\mathrm{Cu}$ response. S288c and YJM789 exhibited the most extreme differences in their abilities to tolerate high doses of $\mathrm{Cu}$ and

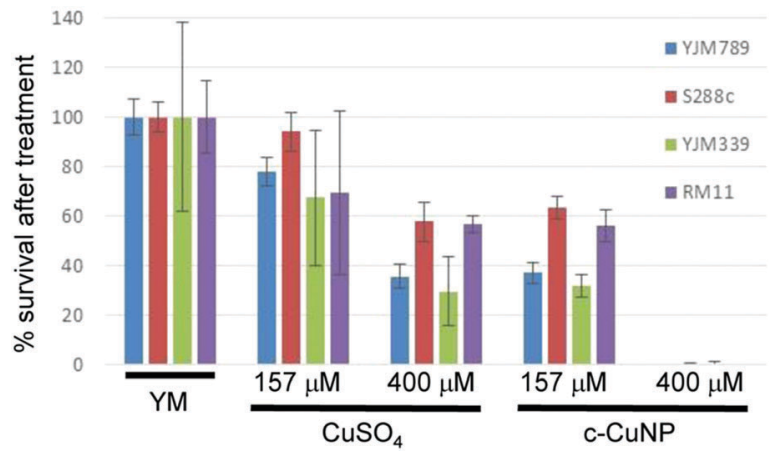

Fig. 5 Acute exposure of yeast to copper nanoparticles. The number of yeast forming colonies grown from cultures grown in YM were normalized to $100 \%$. The viability of yeast after two hours of exposure to $400 \mu \mathrm{M}$ or $157 \mu \mathrm{M}$ of copper in the form of $\mathrm{CuSO}_{4}$ and $\mathrm{c}$-CuNPs is shown as a percentage compared to YM.

moderate doses of c-CuNPs (Fig. 1 and 2). To evaluate potential molecular underpinnings of these responses to $\mathrm{Cu}$, proteomeand genome-wide measurements were carried out. While many mRNAs are known to change in response to copper, ${ }^{7}$ we found only 22 proteins that showed at least 2 -fold changes in S288c in response to $800 \mu \mathrm{M}$ copper by quantitative mass spectrometry (Table 1 and Table S1, ESI $\dagger$ ). Many other proteins showed more than 2-fold changes between strains but not between copper treatments (Fig. S2, ESI $\dagger$ ). 19 out of the 22 copper-responsive proteins showed very little change (less than 1.2-fold change) in $\mathrm{Cu}$-sensitive YJM789 cells when treated with $800 \mu \mathrm{M} \mathrm{CuSO}_{4}$. Among the 19 proteins, Cup1, Fit2, Fet3, and Zrt1 were upregulated, all of which are involved in metal transport (Table 1). Cup1 is a protein that binds $\mathrm{Cu}$ intracellularly and mediates tolerance to high $\mathrm{Cu}$ concentrations. ${ }^{39}$ The S288c genome has two CUP1 alleles annotated with two synonymous SNPs and identical protein sequences (Cup1-1 and Cup1-2), and they cannot be differentiated in proteomics. ${ }^{27} \mathrm{Cup1}^{\mathrm{YJM} 789}$ exhibited a higher abundance in YM relative to $\mathrm{Cup}_{1}{ }^{\mathrm{S} 288 \mathrm{c}}$. Following $\mathrm{Cu}$ exposure, $\mathrm{Cup}_{1} 1^{\mathrm{YJM} 789}$ demonstrated lower abundance relative to $\mathrm{Cup}^{\mathrm{S} 288}$ due to the upregulation of $\mathrm{Cup}^{\mathrm{S} 288 \mathrm{c}}$ combined with little change in Cup1 ${ }^{\text {YJM789 }}$ abundance (Table 1). Fit2 and Fet $3^{40,41}$ are involved in iron (Fe) transport, and Zrt1 is involved in $\mathrm{Zn}$ transport. ${ }^{42}$ Fit2 and Zrt1 exhibited similar protein abundance between S288c and YJM789 in YM. After Cu exposure, Fit2 and Zrt1 showed higher abundance in S288c than in YJM789 because they were upregulated in S288c and changed little in YJM789 (Table 1). As for Fet3, S288c exhibited higher abundance than YJM789 in YM, and the upregulation by $\mathrm{S} 288 \mathrm{c}$ in response to $\mathrm{Cu}$ exposure made strain-specific differences even greater (Table 1).

To further search for genetic loci contributing to $\mathrm{Cu}$ tolerance, we performed a genome-wide linkage study using a hybrid segregant collection ${ }^{17,43,44}$ to find association of genetic variation with differences in $\mathrm{Cu}$ tolerance between S288c and YJM789. 125 segregants from an S288c/YJM789 cross were grown at sub-lethal concentrations of copper $(50 \mu \mathrm{M})$ in liquid culture (Fig. S3A-C, ESI $\dagger$ ). In contrast to previous experiments that used an acute exposure and high $\mathrm{Cu}$ concentration, we used a long exposure and lower dose of $\mathrm{Cu}$ to model the 
adaptive response to low level copper exposure. S288c grew better in low doses of $\mathrm{Cu}$ than in media without additional $\mathrm{Cu}$ (Fig. S3C, ESI $\dagger$ ) as opposed to YJM789, which was strongly inhibited by $\mathrm{Cu}$ (Fig. S3B, ESI $\dagger$ ). In the presence of bathocuproinedisulfonic acid (BCS), a $\mathrm{Cu}$ chelator, $\mathrm{S} 288 \mathrm{c}$ growth decreased (Fig. S3D, ESI $\dagger$ ). The differences in growth of haploid segregants between YM and Cu treatment at 12 hours (mid-log phase) and 18 hours (endpoint) were used as quantitative trait loci (QTL). Using a threshold of LOD (logarithm of odds) >5, three regions of the genome were identified at the mid-log phase (Table S4 and Fig. S4A, ESI $\dagger$ ) and one region was identified at the 18 hour endpoint linked to $\mathrm{Cu}$ resistance (Table $\mathrm{S} 5$ and Fig. S4B, $\mathrm{ESI} \dagger)$. The genetic variations within these regions are most likely associated with differences in copper tolerance between S288c and YJM789.

One region of the genome that was identified in the 12 hour, but not 18 hour, QTL mapping was on chromosome VIII between coordinates 190664 and 223431 , which contains twenty-two genes (Fig. S4C, ESI $\dagger$ ). In the center of this region is the CUP1 locus, and its contribution to $\mathrm{Cu}$ tolerance has been well studied. The common laboratory strain S288c and many other Cu-tolerant strains contain independent amplifications of the CUP1 locus. ${ }^{27,39}$ Other studies have also found that laboratory-evolved strains amplify this region of the genome. ${ }^{45}$ The Saccharomyces Genome Database reference strain, S288c, has two alleles of CUP1 with $Y H R 054 c$, a gene of unknown function, between them. This region is actually amplified seven times in S288c with fourteen copies of the CUP1 gene; YJM789 contains one copy of CUP1 in each repetitive unit that is amplified seven times. ${ }^{27}$

To pinpoint the specific genes that were contributing to $\mathrm{Cu}$ tolerance, we focused on the genes that had amino acid polymorphisms or copy number variation. The region on chromosome XI between 74608 and 92505 (Fig. S4D, ESI $\dagger$ ) contained ten genes, among which MNN4, PEX1, MIA40, MST1, and DHP2 encoded amino acid polymorphisms between S288c and YJM789. Mia40 works with other proteins for the maturation of the mitochondrial fraction of Sod $1 .^{46} \operatorname{Sod} 1$ is a major contributor to converting superoxides to hydrogen peroxide, which is further catalyzed into water and hydrogen ${ }^{47}$ and is important for tolerance to metals, including copper. ${ }^{48}$ In our proteomic analysis, Sod1 levels were not significantly changed between strains or in response to $\mathrm{Cu}$.

Another region that was identified in the endpoint linkage analysis was on chromosome II between coordinates 466289 and 482822 (Fig. S4B, ESI $\dagger$ ). Within this interval is the LYS2 gene, which is mutated in YJM789 as an auxotrophic marker. As this peak was not seen at the 12 hour time point (Fig. S4A, ESI $\dagger$ ), this may be interpreted as Lys 2 becoming required as lysine present in the media was depleted as cells grew to saturation. Therefore, LYS2 may be selected by growth conditions instead of by $\mathrm{Cu}$ treatment.

In both 12 and 18 hour association analyses, one strong peak was shared on chromosome XII between 393415 and 414994 (S6 and Fig. S4A, B, ESI $\dagger$ ), which contained eleven genes (Fig. S4E, ESI $\dagger$ ). One of the genes known to be relevant to $\mathrm{Cu}$ tolerance was $A C E 2$, which encodes the activating transcription factor of CUP1 expression. ${ }^{49}$ However, ACE2 showed no significant change in mRNA abundance in $\mathrm{YM}^{50}$ no amino acid polymorphisms between S288c and YJM789, and minimal change in protein levels in response to $\mathrm{Cu}$ exposure. Near ACE2 was another gene of interest, ZRT2, which encodes a low affinity Zn transporter with five amino acid polymorphisms between S288c and YJM789. ${ }^{33}$ Like Ace2, Zrt2 exhibited less than 2-fold changes in protein abundance between strains or treatments. However, we cannot rule out changes in post-translational modifications of Zrt2 in response to $\mathrm{Cu}$ or the impact of the polymorphisms on transporter function. Therefore, we cloned ZRT2 from each strain, including the endogenous promoters and terminators, into plasmids. When the plasmids were expressed in BY4741 zrt2 deleted yeast, only yeast expressing Zrt2 ${ }^{\text {YJM789 }}$ grew more slowly on media containing $400 \mu \mathrm{M} \mathrm{Cu}$ and showed no change in growth on BCS (Fig. 6A). The polymorphisms within the Zrt2 protein apparently contribute to the $\mathrm{Cu}$-sensitive phenotype of YJM789.

Table 1 Examples of proteins differentially expressed (log 2-fold ratio) between $\mathrm{S}_{288 \mathrm{C}}$ and $\mathrm{YJM789}$ with and without $800 \mu \mathrm{M} \mathrm{CuSO}_{4}$

\begin{tabular}{|c|c|c|c|c|c|c|}
\hline Order in dendro-gram & Systematic name & Protein name & $\mathrm{S} 288 \mathrm{cCu} / \mathrm{S} 288 \mathrm{cYM}$ & YJM789Cu/YJM789YM & YJM789YM/S288cYM & YJM789Cu/S288cCu \\
\hline 81 & YHR053C/YHR055C & Cup1 & 3.477 & 0.196 & 2.585 & -0.686 \\
\hline 82 & YOR382W & Fit2 & 2.448 & -0.117 & 0.167 & -2.387 \\
\hline 84 & YMR058W & Fet3 & 1.180 & -0.105 & -1.429 & -2.630 \\
\hline 93 & YGL255W & Zrt1 & 1.141 & 0.123 & -0.268 & -0.848 \\
\hline 63 & YDR424C & Dyn2 & -1.325 & -0.013 & 0.207 & 1.527 \\
\hline 64 & YAL007C & Erp2 & -1.119 & 0.228 & 0.386 & 1.743 \\
\hline 53 & YHR051W & Cox6 & -1.097 & -0.038 & 1.094 & 2.162 \\
\hline 60 & YOL077W-A & Atp19 & -1.327 & -0.195 & 1.525 & 2.667 \\
\hline 68 & YER057C & Hmf1 & -1.528 & 0.033 & 0.596 & 2.166 \\
\hline 65 & YIL051C & Mmf1 & -1.328 & -0.043 & 0.445 & 1.739 \\
\hline 58 & YBR230C & Om14 & -1.020 & -0.051 & 0.618 & 1.597 \\
\hline 71 & YOR130C & Ort1 & -1.236 & -0.050 & 0.010 & 1.205 \\
\hline 52 & YNL227C & Jjj1 & -1.050 & 0.015 & 0.796 & 1.869 \\
\hline 72 & YDL081C & Rpp1a & -2.002 & -0.009 & -0.373 & 1.629 \\
\hline 70 & YOR236W & Dfr1 & -1.134 & 0.574 & -0.346 & 1.429 \\
\hline 80 & YNL190W & Ynl190w & 1.474 & -0.756 & 3.492 & 1.271 \\
\hline 85 & YPR124W & Ctr1 & -1.966 & -0.494 & -1.380 & 0.101 \\
\hline 35 & YAL046C & Aim1 & -0.168 & -1.334 & 1.136 & -0.021 \\
\hline 96 & YMR173W & Ddr48 & 0.653 & 0.006 & -0.564 & -1.202 \\
\hline
\end{tabular}


In the proteomic analysis, one other metal-responsive protein, Zrt1, was upregulated in S288c, but not in YJM789, when treated with $\mathrm{Cu}$ (Table 1). Zrt1 is a high affinity zinc transporter that is induced in Zn-depleted cells. ${ }^{42}$ While $\mathrm{Zrt1}^{\mathrm{S} 288 \mathrm{c}}$ was upregulated approximately 2-fold by $\mathrm{Cu}$ treatment, other $\mathrm{Zn}$ transporters, including Zrt2 and Zrt3, an intracellular Zn transporter, did not exhibit significant changes in response to $\mathrm{Cu}$ in either strain (Fig. 6B). YJM789 displayed slightly lower Zrt3 expression compared to $\mathrm{S} 288 \mathrm{c}$ regardless of $\mathrm{Cu}$. Due to this association between $\mathrm{Zn}$ transporters and resistance to $\mathrm{Cu}$, we tested whether increased levels of exogenous $\mathrm{Zn}$ could alter the $\mathrm{Cu}$ response of BY4741 and the $\mathrm{Zn}$ transporter mutant yeast lines. The zrt1 and zrt3 knockout lines were sensitive to $1000 \mu \mathrm{M} \mathrm{Cu}$, whereas the zrt2 line was not (Fig. 6C). The addition of $10 \mu \mathrm{M}$ $\mathrm{Zn}$ improved the growth of zrt1, but not zrt3, mutants, and the zrt2 line was still resistant to $\mathrm{Cu}$ and unaffected by supplemental Zn (Fig. 6C). These growth promotion effects were lost at $500 \mu \mathrm{M}$ $\mathrm{Zn}$ in the presence of $1000 \mu \mathrm{M}$ of $\mathrm{Cu}$ (Fig. 6C).

To determine if the relationship between $\mathrm{Cu}$ and $\mathrm{Zn}$ was a more general yeast response, additional yeast strains were tested. When S288c, YJM339, and RM11 were grown in $400 \mu \mathrm{M}$ $\mathrm{Cu}$ in either the soluble form or from c-CuNPs, adding $10 \mu \mathrm{M} \mathrm{Zn}$ resulted in modest growth increases, which were lost or became

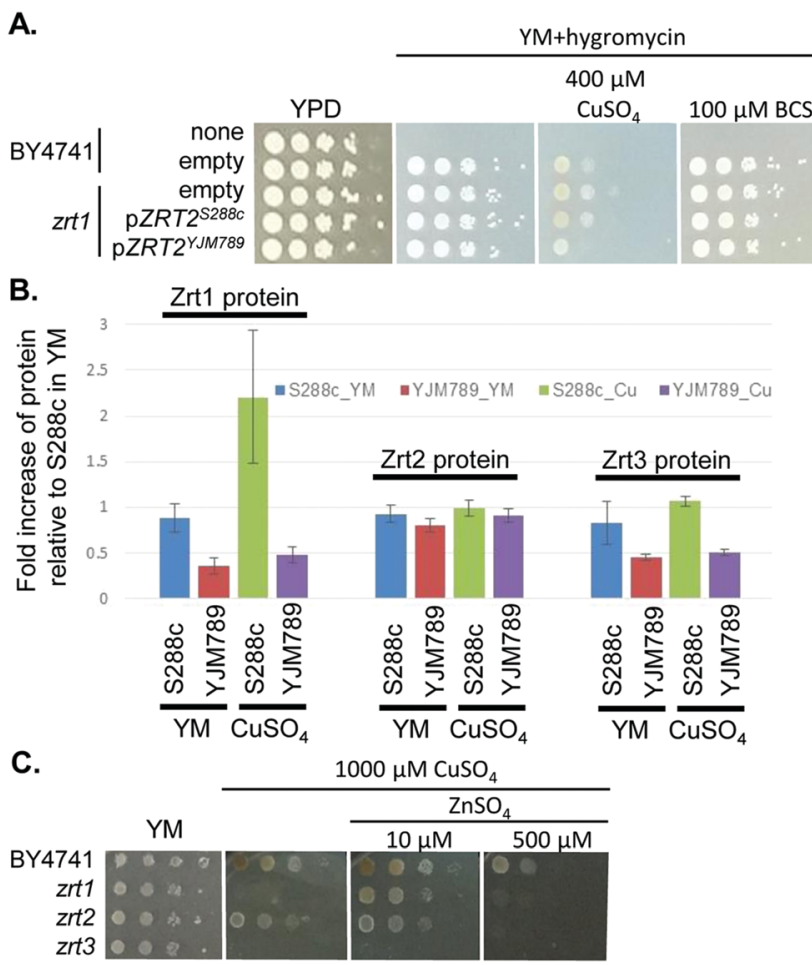

Fig. 6 Impact of zinc transporters and zinc on copper response. (A) Zrt2 allele swaps in S288C (BY4741) in the presence of copper or BCS. ZRT2 plasmids were transformed and maintained in zrt2 mutants by the addition of hygromycin and strains were supplemented with necessary nutrients. (B) Relative protein levels of three different zinc transporters in copper treated cells as measured from proteomic analysis. (C) Serial dilution of S288C (BY4741) yeast with each of the zinc transporters deleted on increasing amounts of copper and zinc. After 2 days of growth at $30{ }^{\circ} \mathrm{C}$ the plates were photographed.

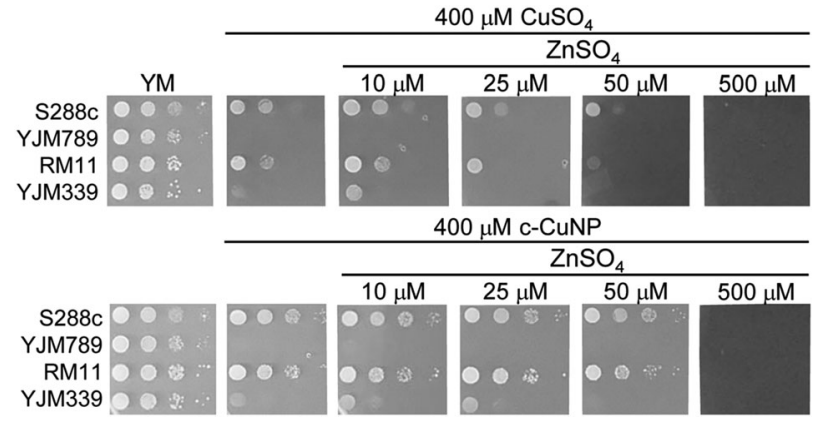

Fig. 7 Addition of zinc to copper nanoparticles altered growth inhibition. Serial dilution of genetically diverse yeast, S288c (GSY147), YJM789, RM11, and YJM339 were grown on minimal media (YM) with indicated levels of copper, c-CuNP and increasing amounts of zinc sulfate. After 2 days of growth at $30^{\circ} \mathrm{C}$, the plates were photographed.

negative at and above $25 \mu \mathrm{M}$ Zn (Fig. 7). In contrast, YJM789 did not respond to supplemental $\mathrm{Zn}$ (Fig. 7). These results indicate that $\mathrm{Zn}$, at low concentrations, plays a role in modulating $\mathrm{Cu}$ toxicity and this benefit may result from different $\mathrm{Zn}$ uptake capacities among yeast strains.

\section{Discussion}

We have characterized the interaction of the genetically diverse model eukaryotic organism, S. cerevisiae, with soluble $\mathrm{Cu}$ and c-CuNPs towards improving future applications of hybrid nanomaterials for microbial control. Copper has been used extensively throughout history as an antimicrobial agent and microorganisms exposed to $\mathrm{Cu}$ gain the opportunity to develop resistance mechanisms to this metal. Metabolic mechanisms that reduce internal metal accumulation or free metal speciation, which will reduce the production of toxic ROS in the cytoplasm, are important in conferring heavy metal resistance. Overcoming existing microbial resistance pathways and altering the balance of metals in cells may enhance the efficacy of existing metal-based antimicrobial materials and aid in the development of novel antimicrobial agents.

\section{Cellulosic copper nanoparticles exhibit enhanced toxicity}

In the current study, the antimicrobial potency of $\mathrm{Cu}$ was increased by the delivery of $\mathrm{Cu}$ in the form of c-CuNPs. Exposure of $157 \mu \mathrm{M}$ copper in NPs was as effective as $400 \mu \mathrm{M}$ copper sulfate in yeast growth inhibition, and the increase in toxicity resulted from enhanced delivery of $\mathrm{Cu}$ to the cytoplasm (Fig. 3 and 5). Flow cytometry evidence and c-CuNP fluorescence suggested that CuNPs bound in large part to the cell walls of $S$. cerevisiae and such binding may presage the transport of $\mathrm{Cu}$ into the cell (Fig. 4B and C). Variation in binding of yeast cells and c-CuNPs mirrored resistance, with low binding strains exhibiting greater resistance to $\mathrm{Cu}$ (Fig. 4A). This differential binding may enhance exposure in $\mathrm{Cu}$ sensitive strains. Based on the size of c-CuNPs $(10-20 \mathrm{~nm}),{ }^{16}$ it is also possible that c-CuNPs were absorbed into $S$. cerevisiae by endocytosis and endocytotic activity varied between the strains. An endocytosis vesicle is 50-80 $\mathrm{nm}$ in S. cerevisiae ${ }^{51}$ and some cells in the current study 
exhibited internal fluorescence (Fig. 4C). Although most of the yeasts with incubated c-CuNPs appeared speckled with c-CuNP on the cell surface, approximately $10 \%$ of the yeast took up c-CuNPs as represented by intracellular FITC staining. We were unable to test if these two subpopulations had differences in survival, but $13 \%$ of the laboratory yeast had internal FITC stained c-CuNPs which was not statistically different from $18 \%$ of the yeast that fail to form colonies after c-CuNP treatment (Fig. 4C). Arrestin mutants in the laboratory strain (S288c background) displayed rescued cellular viability in the presence of c-CuNPs suggesting that endocytosis may be one mechanism of action of c-CuNPs, which would effectively deliver $\mathrm{Cu}$ to the cytoplasm.

\section{Differential expression of metal transporters is linked to toxicity}

Copper uptake and subsequent toxicity, regardless of the mechanism of enhanced delivery of copper via CuNPs, will most likely be governed by the reduction and transport of metals across the plasma membrane and their cellular compartmentation in different strains. In S288c, exposure to $\mathrm{Cu}$ down-regulated the $\mathrm{Cu}$ transporter, Ctr1, ${ }^{52}$ while expression of the $\mathrm{Cu}$ and Fe oxidizer, Fet3, ${ }^{53,54}$ the plasma membrane bound facilitator of iron transport, Fit3, and the high affinity Zn transporter, Zrt1, increased. These patterns suggest that $\mathrm{Cu}$ exposure perturbs trace metal homeostasis and the more resistant $\mathrm{S} 288 \mathrm{c}$ strain responds to these perturbations. ${ }^{40,55}$ YJM789 did not show significant changes in these proteins and we propose that the lack of regulation of $\mathrm{Cu}$ uptake underlies the sensitivity of YJM789 to $\mathrm{Cu}$.

The expression levels of Crt1 tracked cell $\mathrm{Cu}$ concentrations in YJM789 and S288c. Expression is lower in YJM789 than S288c under control conditions, yet reverse under exposure to $\mathrm{Cu}$ (Table 1), leading to YJM789 exhibiting low basal Cu levels in YM media, but increased $\mathrm{Cu}$ under exposure to $\mathrm{Cu}$ (Fig. 3). $\mathrm{S} 288 \mathrm{c}$ regulation of expression more tightly regulates cell $\mathrm{Cu}$ concentrations under these conditions. Thus, S288c apparently has more responsive metabolic regulation of $\mathrm{Cu}$ uptake. Changes in other metal transport genes may reflect mass balance displacement of $\mathrm{Fe}$ and $\mathrm{Zn}$ by $\mathrm{Cu}$ from transporters or secondary stresses requiring additional $\mathrm{Fe}$ or $\mathrm{Zn}$ to overcome toxicity. Fet3 is a ferroxidase required for the reduction of $\mathrm{Fe}(\mathrm{II})$ and subsequent transport across the plasma membrane, and its upregulation may reflect increased demand for $\mathrm{Fe}$ due to inhibition of $\mathrm{Fe}(\mathrm{II})$ transport by $\mathrm{Cu}$ or increased demand for redox metabolism within the cell. Similarly, Fit2 is an iron and iron-siderophore-binding protein expressed on the cell surface ${ }^{40}$ that facilitates $\mathrm{Fe}$ uptake and may be directly regulating $\mathrm{Cu}$ response by adjusting internal iron levels for $\operatorname{Sod} 2$, a mitochondrial superoxide dismutase. ${ }^{56}$

The up-regulation of Zrt1, the high affinity Zn transporter, also points to $\mathrm{Cu}$-induced $\mathrm{Zn}$ limitation in $S$. cerevisiae. High affinity transporters are typically activated by mineral deficiency, and the low $k_{\mathrm{m}}$ for Zrt1 in yeast $(\sim 10 \mathrm{nM})$ suggests that it would be effective in overcoming deficiency. ${ }^{57}$ The fact that supplemental Zn rescued zrt1 knockouts (Fig. 6) and, to a lesser degree, native strains under high $\mathrm{Cu}$ exposure (Fig. 7) suggests that excess $\mathrm{Cu}$ ions at the plasma membrane surface may be impeding the binding of $\mathrm{Zn}$ to $\mathrm{Zn}$ transporters. It is interesting that the more $\mathrm{Cu}$ resistant strain S288c upregulates Zrt1 whereas the sensitive YJM789 does not, suggesting that metal homeostasis responses may be limited in cases where excessive $\mathrm{Cu}$ accumulation does not lead to loss of cellular signaling systems or excessive ROS damage as would occur in strains that cannot limit $\mathrm{Cu}$ accumulation (Fig. 3).

\section{Intracellular copper binding reduces copper toxicity}

Transporters, intracellular sequestration, and chaperonins/ chelation maintain metal concentrations within strict bounds and tightly regulate the balance and potential toxicity of metals within the cytoplasm. In the current study, S288c up-regulated expression of Cup1, the main metallothionein in S. cerevisiae, in response to $\mathrm{Cu}$. YJM789 did not show significant changes in levels of this metal-binding protein in the presence of $\mathrm{Cu}$ and we propose that the lack of response to increased cytoplasmic $\mathrm{Cu}$ increased YJM789 sensitivity to this metal. Unregulated free $\mathrm{Cu}$ concentrations in the cytoplasm will increase the production of ROS and lead to broad disruptions in cell homeostasis.

In support of this, providing certain antioxidants increased the copper levels of all treated strains (Fig. 2). Glutathione can bind copper transported into cells by Ctr1 before delivery to copper chaperones. ${ }^{58}$ More importantly, glutathione and NAC may serve to prime phytochelatin and metallothionein production within $S$. cerevisiae. ${ }^{59,60}$ These peptides/proteins function to regulate internal free metal concentrations and maintain cytoplasmic metal homeostasis. The large increases in $\mathrm{Cu}$ accumulation from both soluble $\mathrm{Cu}$ and CuNPs may reflect enhanced production of these metal-binding systems, the chelation of $\mathrm{Cu}$ intercellularly, and internal storage of nontoxic metal complexes.

\section{Addition of zinc increases copper toxicity}

Although the toxicity of $\mathrm{Cu}$ was alleviated in some strains by the addition of low concentrations of $\mathrm{Zn}$ as discussed above, the antimicrobial activity of $\mathrm{Cu}$ was enhanced in the current study by the application of higher Zn concentrations (Fig. 7). As with $\mathrm{Cu}, \mathrm{Zn}$ plays critical roles as a catalytic and structural cofactor in a wide array of proteins, and maintenance of free $\mathrm{Zn}^{2+}$ concentrations within the cytoplasm is important in maintaining metal homeostasis. ${ }^{61}$ Zinc is transported in the cell by the membrane-bound transporters Zrt1 and Zrt2 and is sequestered in the vacuole by $\mathrm{Zrt3}^{62}$ Given that exposure of yeast to $\mathrm{Cu}$ induces the expression of Zrt1 in Cu-tolerant strains (Table 1), the addition of $\mathrm{Zn}$ into the environment may lead to the overaccumulation of $\mathrm{Zn}$ and subsequent toxicity to $S$. cerevisiae.

When in excess, $\mathrm{Zn}$ will induce many of the same lesions in $S$. cerevisiae as does $\mathrm{Cu}$, including oxidative damage and negative interactions with Fe transport. Thus, the enhanced microbial activity of $\mathrm{Cu}$ and $\mathrm{Zn}$ combined may be due to the additional sympatric lesions induced by Zn. However, there is evidence that the stresses induced by $\mathrm{Cu}$ and $\mathrm{Zn}$ are distinctly different. In a unique multi-metal study of $S$. cerevisiae response to stress, ${ }^{63,64}$ significant differences were found between the response of yeast to $\mathrm{Cu}$ and $\mathrm{Zn}$. While there was some overlap in the common stress responses, such as metal transport and oxidative stress, significant 
groups of differentially expressed genes did not overlap and only two of the 10 most metal-responsive protein-protein and proteinDNA interacting networks were shared. ${ }^{64}$ Thus, there may be limited overlap in the cell's metabolic rescue capacity when, under $\mathrm{Cu}$ exposure, a second divergent metal is introduced. The addition of $\mathrm{Zn}$ to the production of $\mathrm{Cu}$-based nanomaterials would improve the antimicrobial properties of these novel antimicrobial systems and may represent a new approach for public health and food safety.

\section{Author contributions}

XRM carried out the proteomics analysis and LJ developed the proteomics workflow. MJW carried out the microscopy, characterized Zrt2, and performed flow cytometry with JBL. JBL and VAP carried out viability assays. LMW and JRC measured internal copper concentrations. TWC analyzed QTL data. ZRL characterized Cup1 levels. ZRL, JRC, and JEGG wrote the manuscript. JEGG conceived and directed the experiments.

\section{Conflicts of interest}

There are no conflicts to declare.

\section{Acknowledgements}

We thank Mike Snyder for the use of the Orbitrap used in these studies. Randall Mann generously shared his common protein contaminant list. Angela Lee generously gave us the yeast knockout collection. Jenay Grant assisted in confirming the genomic amplification of the CUP1 locus. Flow cytometry was carried out on the WVU Flow Cytometry \& Single Cell Core Fortessa. Microscopy was carried out with the aid of Phil Chapman. This research was funded by the National Science Foundation (grant \#1144676), the West Virginia Clinical and Translational Sciences Institute (grant \#GM104942), and the National Institutes of Health (grant \#OD016165).

\section{Notes and references}

1 H. H. A. Dollwet and J. R. J. Sorenson, Trace elements in Medicine, 1985, vol. 2, pp. 80-87.

2 R. V Lloyd, P. M. Hanna and R. P. Mason, Free Radical Biol. Med., 1997, 22, 885-888.

3 S. V Avery, N. G. Howlett and S. Radice, Appl. Environ. Microbiol., 1996, 62, 3960-3966.

4 D. Quaranta, T. Krans, C. E. Santo, C. G. Elowsky, D. W. Domaille, C. J. Chang and G. Grass, Appl. Environ. Microbiol., 2011, 77, 416-426.

5 M. I. Samanovic, C. Ding, D. J. Thiele and K. H. Darwin, Cell Host Microbe, 2012, 11, 106-115.

6 T. J. Lyons, A. P. Gasch, L. A. Gaither, D. Botstein, P. O. Brown and D. J. Eide, Proc. Natl. Acad. Sci. U. S. A., 2000, 97, 7957-7962.
7 C. Gross, M. Kelleher, V. R. Iyer, P. O. Brown and D. R. Winge, J. Biol. Chem., 2000, 275, 32310-32316.

8 T. Wegner and P. Jones, Wood Fiber Sci., 2005, 37, 549-551.

9 T. H. Wegner and P. H. Jones, Cellulose, 2006, 13, 115-118.

10 T. H. Wegner and E. P. Jones, Nanosci. Technol. Renewable Biomater., 2009, 1, 1-41.

11 J. McCrank, Nanotechnology applications in the forest sector, Natural Resources Canada, 2009.

12 R. J. Moon, A. Martini, J. Nairn, J. Simonsen and J. Youngblood, Chem. Soc. Rev., 2011, 40, 3941-3994.

13 J. Cai, S. Kimura, M. Wada and S. Kuga, Biomacromolecules, 2008, 10, 87-94.

14 T. Zhong, G. S. Oporto, J. Jaczynski and C. Jiang, BioMed Res. Int., 2015, 456834.

15 C. Jiang, G. S. Oporto, T. Zhong and J. Jaczynski, Cellulose, 2015, 1-10.

16 T. Zhong, G. S. Oporto, J. Jaczynski, A. T. Tesfai and J. Armstrong, Wood Fiber Sci., 2013, 45, 1-8.

17 L. M. Steinmetz, H. Sinha, D. R. Richards, J. I. Spiegelman, P. J. Oefner, J. H. McCusker and R. W. Davis, Nature, 2002, 416, 326-330.

18 J. W. Wenger, K. Schwartz and G. Sherlock, PLoS Genet., 2010, 6, e1000942.

19 J. H. McCusker, K. V Clemons, D. A. Stevens and R. W. Davis, Genetics, 1994, 136, 1261-1269.

20 A. R. Borneman, A. H. Forgan, I. S. Pretorius and P. J. Chambers, FEMS Yeast Res., 2008, 8, 1185-1195.

21 R. K. Mortimer, P. Romano, G. Suzzi and M. Polsinelli, Yeast, 1994, 10, 1543-1552.

22 M. J. McCullough, K. V Clemons, C. Farina, J. H. McCusker and D. A. Stevens, J. Clin. Microbiol., 1998, 36, 557-562.

23 A. H. Tong, M. Evangelista, A. B. Parsons, H. Xu, G. D. Bader, N. Page, M. Robinson, S. Raghibizadeh, C. W. Hogue, H. Bussey, B. Andrews, M. Tyers and C. Boone, Science, 2001, 294, 2364-2368.

24 J. R. Wisniewski, A. Zougman and M. Mann, J. Proteome Res., 2009, 8, 5674-5678.

25 A. C. Gerstein, J. Ono, D. S. Lo, M. L. Campbell, A. Kuzmin and S. P. Otto, Genetics, 2015, 199, 555-571.

26 A. Hodgins-Davis, A. B. Adomas, J. Warringer and J. P. Townsend, Genome Biol. Evol., 2012, 4, 1061-1079.

27 Y. Zhao, P. K. Strope, S. G. Kozmin, J. H. McCusker, F. S. Dietrich, R. J. Kokoska and T. D. Petes, G3, 2014, 2259-2269.

28 J. C. Fay, H. L. McCullough, P. D. Sniegowski and M. B. Eisen, Genome Biol., 2004, 5, R26.

29 D. J. Kvitek, J. L. Will and A. P. Gasch, PLoS Genet., 2008, 4, e1000223.

30 T. Torok, R. K. Mortimer, P. Romano, G. Suzzi and M. Polsinelli, J. Ind. Microbiol., 1996, 17, 303-313.

31 R. B. Brem, G. Yvert, R. Clinton and L. Kruglyak, Science, 2002, 296, 752-755.

32 R. K. Mortimer and J. R. Johnston, Genetics, 1986, 113, 35-43.

33 J. M. Cherry, E. L. Hong, C. Amundsen, R. Balakrishnan, G. Binkley, E. T. Chan, K. R. Christie, M. C. Costanzo, S. S. Dwight, S. R. Engel, D. G. Fisk, J. E. Hirschman, B. C. Hitz, K. Karra, C. J. Krieger, S. R. Miyasato, R. S. Nash, J. Park, 
M. S. Skrzypek, M. Simison, S. Weng and E. D. Wong, Nucleic Acids Res., 2012, 40, D700-D705.

34 O. W. Tawfik, C. J. Papasian, A. Y. Dixon and L. M. Potter, J. Clin. Microbiol., 1989, 27, 1689-1691.

35 A. M. Sadowska, Ther. Adv. Respir. Dis., 2012, 6, 127-135.

36 C. H. Lin, J. A. MacGurn, T. Chu, C. J. Stefan and S. D. Emr, Cell, 2008, 135, 714-725.

37 E. Georgatsou, L. A. Mavrogiannis, G. S. Fragiadakis and D. Alexandraki, J. Biol. Chem., 1997, 272, 13786-13792.

38 Y. Yamaguchi-Iwai, M. Serpe, D. Haile, W. Yang, D. J. Kosman, R. D. Klausner and A. Dancis, J. Biol. Chem., 1997, 272, 17711-17718.

39 M. Karin, R. Najarian, A. Haslinger, P. Valenzuela, J. Welch and S. Fogel, Proc. Natl. Acad. Sci. U. S. A., 1984, 81, 337-341.

40 O. Protchenko, T. Ferea, J. Rashford, J. Tiedeman, P. O. Brown, D. Botstein and C. C. Philpott, J. Biol. Chem., 2001, 276, 49244-49250.

41 D. M. De Silva, C. C. Askwith, D. Eide, J. Kaplan, D. M. De Silva, C. C. Askwith, D. Eide and J. Kaplan, J. Biol. Chem., 1995, 270, 1098-1101.

42 H. Zhao and D. Eide, Proc. Natl. Acad. Sci. U. S. A., 1996, 93, 2454-2458.

43 J. E. G. Gallagher, W. Zheng, X. Rong, N. Miranda, Z. Lin, B. Dunn, H. Zhao and M. P. Snyder, Genes Dev., 2014, 28, 409-421.

44 E. Mancera, R. Bourgon, A. Brozzi, W. Huber and L. M. Steinmetz, Nature, 2008, 454, 479-485.

45 G. M. Adamo, M. Lotti, M. J. Tamas and S. Brocca, Microbiology, 2012, 158, 2325-2335.

46 A. Varabyova, U. Topf, P. Kwiatkowska, L. Wrobel, M. KausDrobek and A. Chacinska, FEBS J., 2013, 280, 4943-4959.

47 K. T. Tamai, E. B. Gralla, L. M. Ellerby, J. S. Valentine and D. J. Thiele, Proc. Natl. Acad. Sci. U. S. A., 1993, 90, 8013-8017.
48 M. M. Pena, K. A. Koch and D. J. Thiele, Mol. Cell. Biol., 1998, 18, 2514-2523.

49 G. Butler and D. J. Thiele, Mol. Cell. Biol., 1991, 11, 476-485.

50 W. Zheng, H. Zhao, E. Mancera, L. M. Steinmetz and M. Snyder, Nature, 2010, 464, 1187-1191.

51 C. Buser and D. G. Drubin, Microsc. Microanal., 2013, 19, 381-392.

52 S. A. Knight, S. Labbe, L. F. Kwon, D. J. Kosman and D. J. Thiele, Genes Dev., 1996, 10, 1917-1929.

53 D. de Silva, S. Davis-Kaplan, J. Fergestad and J. Kaplan, J. Biol. Chem., 1997, 272, 14208-14213.

54 C. Askwith, D. Eide, A. Van Ho, P. S. Bernard, L. Li, S. DavisKaplan, D. M. Sipe and J. Kaplan, Cell, 1994, 76, 403-410.

55 J. A. Stadler and R. J. Schweyen, J. Biol. Chem., 2002, 277, 39649-39654.

56 A. Naranuntarat, L. T. Jensen, S. Pazicni, J. E. Penner-Hahn and V. C. Culotta, J. Biol. Chem., 2009, 284, 22633-22640.

57 D. J. Eide, Biochim. Biophys. Acta, Mol. Cell Res., 2006, 1763, 711-722.

58 E. B. Maryon, S. A. Molloy and J. H. Kaplan, Am. J. Physiol., 2013, 304, C768-C779.

59 R. Kneer, T. M. Kutchan, A. Hochberger and M. H. Zenk, Arch. Microbiol., 1992, 157, 305-310.

60 J. Wünschmann, A. Beck, L. Meyer, T. Letzel, E. Grill and K. J. Lendzian, FEBS Lett., 2007, 581, 1681-1687.

61 C. W. MacDiarmid, L. A. Gaither and D. Eide, EMBO J., 2000, 19, 2845-2855.

62 F. Winston, C. Dollard and S. L. Ricupero-Hovasse, Yeast, 1995, 11, 53-55.

63 X. Liu, J. Jia, R. Popat, C. A. Ortori, J. Li, S. P. Diggle, K. Gao and M. Cámara, BMC Microbiol., 2011, 11, 26.

64 Y. H. Jin, P. E. Dunlap, S. J. McBride, H. Al-Refai, P. R. Bushel and J. H. Freedman, PLoS Genet., 2008, 4, e1000053. 